\title{
Search depth, knowledge characteristics, and innovation performance
}

\author{
Jianfeng Wu', Yonggui Wang and Sichao Li
}

* Correspondence: wujf@uibe.edu.cn School of Business, University of International Business and Economics, Beijing 100029, China

\begin{abstract}
This study takes a contingent perspective regarding the relationships among a firm's technological search depth, the characteristics of its knowledge, and its product innovation performance. While a firm's search patterns directly influence innovative output, their effectiveness is moderated by the internal context of knowledge: knowledge depth, knowledge scope, and related technological opportunities. Findings from the US electrical medical device industry (1990 to 2000) provide general support for these arguments.
\end{abstract}

Keywords: Search depth; Knowledge stock; Product innovation

\section{Background}

Research in strategic management and innovation suggests that part of the base for heterogeneity in innovative capabilities resides in firms' search behaviors for new products (Cyert and March 1963; Nelson and Winter 1982; March 1991; Katila and Ahuja 2002). Firms tend to conduct local search around current areas of expertise (March 1991; Stuart and Podolny 1996) due to the effects of outcome predictability, cost efficiency, and technological confidence associated with internal exploitation (March 1991). However, local search may constrain a firm's sensitivity to external changes in customer tastes, technological frontiers, and competitive dynamics, which may turn core competence into core rigidities (Leonard-Barton 1992). To avoid such competency traps, firms attempt to explore knowledge elements that reside outside their current technological domains and their organizational boundaries (Katila and Ahuja 2002; Rosenkopf and Nerkar 2001).

Developmental resources are scarce for most firms, however, and this suggests that exploration activities will need to compete for resources against those projects focused on the exploitation of current resources and capabilities (March 1991). This raises the issue of how to balance exploitation and exploration. Current research, however, has not provided clear answers on how to balance exploitation and exploration in technological search. For instance, both positive linear and curvilinear relationships have been found between exploration and innovative performance in empirical studies (e.g., Katila and Ahuja 2002; McEvily and Yao 2004).

Following Pisano (1996), this study takes a contingent perspective and argues that the effectiveness of search behaviors is moderated by the characteristics of a firm's

(c) 2014 Wu et al.; licensee Springer. This is an Open Access article distributed under the terms of the Creative Commons Attribution License (http://creativecommons.org/licenses/by/2.0), which permits unrestricted use, distribution, and reproduction in any medium, provided the original work is properly cited. 
knowledge base. As a firm explores new opportunities or solves new problems, its knowledge will be a starting point for future search. A firm's knowledge base influences the direction and effectiveness of its search behaviors (Yayavaram 2003). We investigate how three characteristics of a firm's knowledge base (depth, scope, and technological opportunities) affect its innovative results.

Our hypotheses are tested with data from firms in the US electrical medical device industry (standard industrial classification $(\mathrm{SIC})=3,845$ ) over the period from 1990 to 2000. Our findings indicate that the characteristics of a firm's knowledge base are closely related to its search behaviors. When a firm seeks to innovate, it must take into consideration its current knowledge base and must be cautious about the degree of internal exploitation.

\section{Literature review}

Firms can innovate by searching and integrating new knowledge elements (Cohen and Levinthal 1990). Typically such search behaviors can be classified as exploitation and exploration (March 1991; Stuart and Podolny 1996). March defines exploitation as the 'refinement and extension of existing competences, technologies, and paradigms' (1991: 85 ) and claims that the returns from exploitation tend to be positive, proximate, and predictable. The alternative, exploration, is 'experimentation with new alternatives' (March 1991: 85), and its returns are uncertain, distant, and often negative. Compared to exploitation, exploration is more likely to be associated with risk taking, uncertainty, and a long-term orientation.

Because of the risks associated with exploration, firms may prefer exploitation when it is possible. However, too much exploitation will reduce a firm's adaptive capabilities and, from a long-term perspective, may impair its competitive advantage. To avoid potential core rigidities and remain competitive, firms often experiment with new technologies (Leonard-Barton 1992; Bierly and Chakrabarti 1996). Firms that engage in exploration and integrate novel, emerging, and pioneering technologies into their operations will be more likely to generate influential knowledge than firms engaged in more limited local search processes (Ahuja and Lampert 2001). This suggests the need for a balance between exploitation and exploration.

Recently Katila and Ahuja (2002) have proposed two dimensions to help better capture a firm's search behavior: search depth and search scope. Search depth refers to 'the degree to which search revisits a firm's prior knowledge' (Katila and Ahuja 2002: 1184). This reflects a firm's capability in identifying new opportunities for existing knowledge elements. Search scope means 'the degree of new knowledge that is explored' (Katila and Ahuja 2002: 1184), which captures a firm's willingness and capability in exploring and integrating new ideas, which is similar to the so-called 'absorptive capacity' (Cohen and Levinthal 1990). These dimensions are extensions of March's (1991) distinction between exploitation and exploration and allow for the possibility that a firm might be active at both exploiting existing technologies and exploring new knowledge. Hence, the use of depth and scope ideas permits a more detailed and complete description of a firm's search behaviors.

Prior research suggests that search depth and search scope have different associations with the innovative results achieved by firms. For instance, Katila and Ahuja (2002) 
measure innovation performance by the number of new designs in the robotics industry and examine how a firm's search patterns affect its rate of new product introductions. They find that when a firm continues searching for new knowledge, more new products come out. Moreover, there is an inverted-U relationship between search depth and innovation performance, implying that too much internal search might constrain a firm's capability to find new ideas and designs. They also identify a significant and positive interaction result between search depth and scope which suggests a complementary relationship between them.

While a firm's search patterns may affect its innovative performance, research results are inconclusive and even contradictory regarding how. Some studies find that exploration has a positively linear relationship with new product innovation. For example, Katila and Ahuja (2002) observed that in robotics industry, the more new knowledge elements are searched, the more new products are created. Rosenkopf and Nerkar (2001) find a strong relationship between search scope and the impact of new inventions in the optical disk industry. As firms search beyond their technological domains and organizational boundaries (radical search), they are more likely to create influential inventions. Along with these results, however, studies also show that moderate exploration helps create more new products. For example, McEvily and Yao (2004) find an inverted- $\mathrm{U}$ relationship between exploration and new product innovation.

The above studies focus on the effect of search without considering the firm's knowledge base, which reflects a firm's competence and experience in special knowledge domains. This could be misleading as Penrose has argued, '... unknown and unused productive services [from existing resources] immediately become of considerable importance, not only because the belief that they exist acts as an incentive to acquire new knowledge, but also because they shape the scope and direction of the search for knowledge' (1959: 77-79). Thus, the context of current knowledge should influence the relationship between search behaviors and innovative performance.

Pisano (1996) provides two insights into this question. First, the resource-based view emphasizes the value of knowledge and organizational competencies and conceives them as competitive assets, a rather limited vision. More attention is needed on the interaction between the firm's knowledge base and its competencies. Second, firms' knowledge bases are idiosyncratic and heterogeneous, even within the same industry or the technological area. In the setting of knowledge creation, then, there is no 'best' knowledge strategy. Rather, 'the appropriateness of different practices and approaches may vary depending on characteristics of the knowledge environment' (Pisano 1996: 97).

To test this proposition, Pisano (1996) compares the influence of different learning types in two industries that differ in research settings: synthetic chemicals and biotechnology. Empirical results show that a greater input in the research phase of a chemical process development results in shorter lead times, confirming the proposal that learning before doing is more important in the chemical industry. On the other hand, results show that learning by doing is appropriate when organizations do not possess required knowledge, such as in biotechnology. Thus, the value of organizational capabilities is dependent on the characteristics of a firm's knowledge base.

This study applies Pisano's contingent perspective and argues that the relative effectiveness of exploitative search will depend on a firm's existing knowledge base. While previous studies have examined the interaction between explorative search and a firm's 
knowledge base (Wu and Shanley 2009), this research attempts to focus on the role of exploitative search behaviors. The following section develops hypotheses on the main effects of search behaviors and the moderating roles of the firm's current knowledge base.

\section{Hypotheses}

Because of bounded rationality and limited resources, firms tend to search around their existing technological domains where their competences reside (Nelson and Winter 1982; Cohen and Levinthal 1990; March 1991; Stuart and Podolny 1996). As the depth of search increases, we would expect, at least technically, that more new products will be created, since the firm has already accumulated extensive experience in current knowledge domains (March 1991; Fleming 2001). Searching locally also is more likely to avoid technological mistakes and reduce experimentation time. As a result, with increasing search depth, more new knowledge is likely to be discovered.

Strategically, local search brings other benefits. First, it makes competitive imitation less likely since potential entrants will need to master early-generation knowledge in order to succeed. However, those early technologies may require a long time to build and understand or may be protected by patents. Second, the firm may enjoy economies of scope in the development of new products. When technologies are incrementally built up, current complementary assets will be useful in supporting next-generation products, which provides cost advantages to the firm relative to competitors. Finally, focusing search on a specific domain can enable the firm to build a reputation in the niche (Bierly and Chakrabarti 1996). If a firm continuously improves existing products and introduces new but related generations, it is more likely that these products will be developed with customer needs in mind (Christensen 2000). Customers, in turn, will be more aware of the firm's innovative capabilities and will be more loyal to its products.

However, the benefits of exploitation do not last forever. From a technological point of view, there are decreasing returns to physical scaling (Sahal 1985). That is, given a set of knowledge components, the number of possible recombinations is limited. Kim and Kogut (1996) and Fleming (2001) suggest that when a group of technologies is repeatedly applied, the potential for future combinations eventually will be exhausted. Part of this effect comes from the diminished ability of developers to conceive new applications. The 'imaginary life cycles' (Henderson 1995) of new product developers will tend to petrify, making them less likely to incorporate new components into their products. Finally, deep search within existing knowledge domain may form competency traps and lead to core rigidity (Leonard-Barton 1992).

These considerations suggest that beyond a certain level of search depth, we would expect that the costs of local search will be higher than the benefits. This implies an inverted-U relationship between a firm's exploitation of existing knowledge and its capability in new product innovation and suggests the following hypothesis:

- Hypothesis 1: There is an inverted-U relationship between search depth and product innovation, given all else equal. 


\section{Moderating effects of the knowledge base on search depth}

Although a deep search around areas of current expertise is less risky and costly than an exploratory search, there are still costs associated with it (Leonard-Barton 1992). When should a firm conduct deep search within its current knowledge domains as opposed to exploring new domains? The innovation literature suggests that both a firm's external environment and its internal knowledge base affect the effectiveness of deep search. This study concentrates on the internal knowledge base while examining firms that share a general external environment (electrical medical devices). Under these conditions, the expectation is that when a firm's current knowledge base is diverse and rich in opportunities, deep search will be more productive.

Knowledge depth and search depth Deep understanding in a specific technological area comes from deliberate investment, active learning, and historical accumulation. Due to resource constraints, a firm can invest in only a limited number of technological areas in order to establish such technological superiority. Once this knowledge expertise is developed, the firm tends to search within current domains and exploit potential opportunities. However, as the depth of the knowledge base increases, the chance of discovering novel applications and new knowledge elements diminishes (Kim and Kogut 1996; Fleming 2001). Deep search may lead to core rigidities that significantly hamper a firm's ability to adapt to competitive dynamics (Leonard-Barton 1992). Thus, we propose that

- Hypothesis 2: The relationship between search depth and product innovation will be negatively moderated by knowledge depth.

Knowledge scope and search depth A firm with a diverse knowledge base possesses expertise in many domains. This provides an opportunity for a firm to discover new linkages among existing knowledge elements. Given a diverse knowledge pool, a firm skilled in combining its competences can create more new knowledge than its rivals. In addition, the more diverse a firm's knowledge base is, the more linkages are created. This suggests that deep exploitative search will be most appropriate for a highly diverse knowledge base.

When a firm's knowledge base is very specialized, however, covering only a limited number of domains, internal exploitation may impair a firm's long-term performance. Given a limited space in which to discover new knowledge linkages, excessive exploitation may turn a firm's core competence into core rigidity. Therefore, when a firm has a limited number of knowledge domains, it is less likely to maintain competitive advantage if the degree of internal exploitation is high. When the knowledge base is highly diverse, internal exploitation will help the firm maintain high performance. This suggests the following hypothesis:

- Hypothesis 3: The relationship between search depth and product innovation will be positively moderated by knowledge scope. 
Technological opportunity and search depth Technological opportunity refers to the ease of achieving innovations and improving techniques (Fung 2004). Industries differ systematically in terms of the strength and sources of technological opportunities (Fung 2004; Klevorick et al. 1995). Such differences can be represented by three measures (Fung 2002): knowledge spillover, inter-firm research overlap, and scope of research. Fung $(2002,2004)$ operationalized these measures with patent information and found that technological opportunities were significantly associated with differences in research productivity in three industries: chemical, computers, and electronics. Similarly, Klevorick et al. (1995) identified three sources of technological opportunities: advances in scientific understanding and technique, advances originating from other industries and from other private and government institutions, and feedback from an industry's own technological advances. Differences in technological opportunities exist not only across industries but also across firms in the same industry, as evidenced by McGrath and Nerkar (2004) in their study of pharmaceutical firms.

We expect that firms will find it worthwhile to conduct deep search within their current knowledge base when that base is perceived to be rich in technological opportunities. This is likely for several reasons. To start with, the perceived benefits of a domain may more than offset the costs of exploitation and make the domain absolutely more desirable. In addition, technologies with high potential tend to require more novel development projects, whose first generations are primitive and rudimentary. They will often require additional deep search by first movers to make the necessary changes and produce the more commercially feasible versions that justify a firm's heavy initial developmental expenditure. If the inventing firm stops further exploitation of a novel technology, others can quickly catch up without the same risky initial investments. Finally, high levels of perceived opportunities may prove a constant spur to entry. This means that in order to stay competitive and prevent imitation and expropriation of rents, the inventing firm will need to remain innovative and continuously improve its technologies (Ahuja 2003). These considerations suggest the following hypothesis:

- Hypothesis 4: The relationship between search depth and product innovation will be positively moderated by technological opportunities associated with the knowledge base.

\section{Methods}

\section{Sample and data}

This study uses all public electrical medical device firms in the USA between 1990 and 2000. Focusing on firms that share an external environment allows for the control of crossindustry variation. Such variation is important for understanding how context influences firm decision making but is not central to the interest of this study in how the characteristics of a firm's knowledge base influence its search behaviors.

There are two significant clarifying observations to be made about our use of this industry in the study. First, to keep up with the pace of technological development, the firms in this industry must rely extensively on in-house research and development (R\&D) investment or gain access to new techniques through licensing and/or acquisitions. The average firm R\&D expenditure accounts for $15 \%$ of annual sales. Second, patenting is a popular action in this 
industry. There have been more than 75,000 patents issued for the whole medical device industry by the US Patent and Trademark Office over the past 30 years. In order to avoid potential losses, firms tend to get their proprietary technologies patented.

Sample data are collected from the Standard and Poor's COMPUSTAT database (New York, NY, USA) with SIC equal to 3,845. This sample includes both active and inactive firms. We select firms with at least 3 years of financial data, which results in 152 public firms and 1,157 firm-year observations. After adjustments for extreme values and missing data, the final sample for analysis consists of 141 public firms and 955 firm-year observations.

Measures

Dependent variable

Our general interest is in explaining innovation performance. We measure product innovation by the number of new product introductions, measured by the number of new products that a medical device firm has applied to Center for Devices and Radiological Health (CDRH) of Food and Drug Administration (FDA) and received approval for. CDRH keeps track of all successfully approved new medical devices. This database contains extensive information related to a new device, including the owner, the date of approval, the class of device, and the medical specialty area.

\section{Independent variables}

Search depth reflects the extent to which a firm exploits its current knowledge. If the degree of internal search is high, we would expect a high degree of citation ratio of its current knowledge elements. Therefore, we use the following formula to measure exploitation, which has been used by Katila and Ahuja (2002):

$$
\text { Search depth }_{i t}=\frac{\sum_{y=t-5}^{t-1} \text { Repetition count }_{i y}}{\text { Total citations } i t}
$$

This formula captures the portion of total citations in year $t$ for firm $i$ that has been used in the past 5 years. Argote (1999) suggests a 5 -year period because in high-tech industries, the value of technologies depreciates quickly.

Knowledge depth is measured by the average number of patents in each of the classes listed in a firm's knowledge base. When a firm has deep understanding in a specific knowledge area, we would expect more knowledge elements created by the firm in that domain.

Knowledge scope is calculated by using the number of technological classes that a firm's patents have been assigned to (Ahuja and Katila 2001; Fleming 2001). This study follows Lerner (1994) in using International Patent Classification (IPC) system instead of US patent classification system to capture the technological classes. We use the following formula to measure the width of each firm's knowledge scope:

$$
\text { Knowledge scope } \mathrm{e}_{i t}=1-\sum_{p=1}^{q}\left(\frac{M_{p}}{N}\right)^{2},
$$

where $N$ is the total number of patents in firm $i$ 's knowledge base in year $t, M_{p}$ is the number of patents that are classified in a technological class $p$, and $q$ is the total number of four-digit IPC classes covered by the knowledge base in year $t$. 
We employ the number of claims that a firm's patents have received to operationalize technological opportunities. The formula is as follows:

$$
\text { Technological opportunities }_{i t}=\frac{\sum_{p=1}^{N} \text { Claim }_{p}}{N},
$$

where $N$ is the total number of patents in firm $i$ 's knowledge base in year $t$ and Claim is the number of claims that patent $p$ has received.

Claims represent the details of a patent's future usages and can be treated as building blocks of an invention. Thus, this number can capture the scope of an invention (Hall et al. 2001; Lanjouw and Schankerman 1999). For example, McGrath and Nerkar (2004) used the number of patent claims as a measure of technological opportunities in pharmaceutical industries. They found that as technological opportunities associated with a patent increase, the more likely that a firm will make further $R \& D$ investments to exploit those potentials. Thus, the number of claims represents participants' judgments of a patent's future opportunities.

\section{Control variables}

As general economic conditions and market environments can change over time, firms may vary in their propensities to introduce new innovations (e.g., Ahuja 2000; Katila and Ahuja 2002). To control for this time effect, we include a series of year dummies (1990 to 1999) into our regression model. The omitted year is 'year 2000'.

Current studies indicate that diversification affects firms' innovative capabilities, although in different directions (e.g., Williamson 1975; Hill et al. 1988). For example, Williamson (1975) suggests that an internal capital market exists in a multi-product firm, which can provide cross-subsidization among different product areas and encourage corporate managers to take risky R\&D projects. Thus, a positive relationship should exist between product diversification and innovation. Conversely, Hill et al. (1988) argued that there were substantial agency costs in M-form firms, where division managers tended to avoid risky investments and sacrifice long-term $R \& D$ projects to more short-term financial performance. Therefore, they claim a negative effect of diversification on product innovation. Since there is no clear-cut answer to the role of diversification, this study controls for it in the regression model and makes no direct inferences about the sign.

One thing to point out is that diversification reflects the scope of a firm's products, rather than the scope of its technologies. Based on the same technology, a firm may introduce several different products targeted for different groups of customers. So, while diversification may be correlated with the knowledge scope, it may also be correlated with other factors; hence, the relationship is not clear in current theories. Therefore, we include diversification as a control variable.

Diversification is calculated as an entropy measure: Diversification $=\Sigma P_{j} \ln \left(1 / P_{j}\right)$, where $P_{j}$ is the percentage of firm sales in business segment $j$ and $\ln \left(1 / P_{j}\right)$ is the weight for each segment $j$ (Palepu 1985). Segment sales information is drawn from the COMPUSTAT segment database.

Henderson and Cockburn (1996) argued that larger pharmaceutical firms can enjoy economies of scale in searching for new drugs. This is associated with the cost spreading effect over larger research programs. They point out that $R \& D$ activities in the pharmaceutical industry involve substantial fixed costs on compound library, computer 
resources, or research equipment. The sharing of these resources reduces the unit cost of each research program as the overall research efforts increase. To control for the effect of economies of scale, we included the natural log of annual research and development expenditure as a proxy for research size.

Financial performance is also controlled. Investment in R\&D is risky in high-tech industries. To guarantee long-term performance and continuity of new products, firms must garner enough financial resources to support technological research. Previous profitability helps a firm accumulate slack resources that facilitate subsequent search (Cyert and March 1963). Thus, a positive relationship is expected between financial performance and innovation performance. We include return on assets (ROA) to control for this effect. This measure has been used extensively in other innovation studies (e.g., Ahuja 2000; Katila and Ahuja 2002). Thus, using ROA as the performance measure facilitates comparisons across studies. Besides, other performance measures such as return on sales have a high correlation with ROA (e.g., Steensma and Corley 2000).

Finally, we controlled for the speed of yearly demand growth for each firm. As suggested by Ahuja (2003), the firm's decision to invest in a particular technological space is affected by the expected level of demand. Theoretically, a firm is more likely to conduct deep search within current technological domains if the market demand for its current products keeps rising. In order to control for this effect, we use data on firm sales to compute the rate of demand growth over the previous year as the proxy for expected demand growth.

\section{Regression models}

There are two specific attributes associated with our data that are important for specifying regression models. First, our dependent variable is a non-negative count measure. An appropriate method dealing with this type of dependent variable would be a Poisson regression or negative binomial regression. The former assumes equality between the mean and the variance of the dependent variable, which is violated in our sample. As a result, this study applies negative binomial regression model to analyze the data (Hausman et al. 1984). Second, there are repeated observations for the same firm. Therefore, our data is the combined time-series cross-sectional panel data. This might lead to unobserved heterogeneity due to firm level effects. To control for this, we can use both random effects and fixed effects models. Maddala (1987) notes that the choice of regression model depends upon the statistical properties of the implied estimators. When the number of cross section is large and the number of observations per firm is small, it is not possible to consistently estimate a fixed effects model. Therefore, we apply random effects negative binomial regression (Hausman et al. 1984).

Accordingly, we specify the following negative binomial regression model:

$$
P_{i, t+1}=\exp \left(\text { knowledge stock }_{i, t}, \text { search depth }_{i, t}, \text { interaction effects }_{i, t}, \text { control variables }_{i, t}\right),
$$

where $P_{i, t+1}$ is the number of new products in year $t+1$; knowledge stock $_{i, t}$ captures the characteristics of a firm's knowledge base in year $t$, which is measured on the basis of all patents in the past 5 years $(t-5, t-1)$; search behaviors ${ }_{i, t}$ indicates the levels of search depth and scope in year $t$; and control variables ${ }_{i, t}$ are those controlled measures in year $t$. 


\section{Results and discussion}

Table 1 lists the descriptive statistics and correlations of our interested variables. We noticed that there are a number of significant correlations among the independent variables. For instance, there is a high correlation between knowledge depth and search depth (correlation coefficient $=0.49$ ), which confirms the argument that firms tend to search locally around their current core competency. Also, we found that knowledge depth was highly related to technological opportunities (correlation coefficient $=0.43$ ).

To test for multicollinearity, we examine the variance inflation factor (VIF) for each independent variable. There is no ideal threshold value to judge the significance of multicollinearity, but a common rule of thumb is that if VIF is greater than 4.0, there might be a problem. If VIF is greater than 10.0, then we conclude that multicollinearity is a serious problem (Madansky 1988). As shown in Table 2, the highest VIF (year 1997) is 3.31, while most VIFs of our key explanatory variables are less than 3 . Thus, multicollinearity should not be a major problem in our regression analysis. We also follow the suggestions by Cronbach (1987) and center our knowledge base and search variables on their means before creating interaction terms. This helps reduce the correlation between the first power and second power terms, as well as the correlation between separate and interactive effects.

Table 3 reports the regression results for new product introduction. Model 1 includes all control variables and three knowledge variables. The coefficients of research size and performance are both positive and significant, indicating that good performers and large R\&D investors are more likely to introduce new products into the market. Among the three measures of knowledge base, only knowledge depth plays a significant and positive effect on new product introduction.

Models 2 and 3 enter the linear and quadratic forms of search variables, respectively. The results show that search depth has a marginally inverted-U shape relationship with new product generation. The squared coefficient of search depth is -0.25 in model 3, with a $p$ value less than 0.1 . Therefore, hypothesis 1 is marginally supported.

To test hypotheses 2 to 4 , we entered each interaction into the models sequentially. In model 4, the interaction between search depth and knowledge depth was added. Compared to model 3, model 4 had a significant incremental chi-square of 3.8. The coefficient of the interaction term is negative and significant, suggesting a negative moderating effect of knowledge depth on search depth. This supports hypothesis 2. Hypothesis 3 proposes that when knowledge scope is wide, deep search will be more productive. This is supported in model 5, which contains a significant and positive effect of the interaction term between search depth and knowledge scope. When the interaction between search depth and technological opportunities is included in model 6, its coefficient is positive, as expected, but lack statistical significance. Therefore, hypothesis 4 is not statistically supported.

\section{Conclusion}

This study examines the moderating effects of knowledge characteristics on the relationship between search depth and innovative performance. The main argument suggests that while search behaviors directly affect the generation of new knowledge, their effectiveness will be moderated by the depth, scope, and technological opportunities associated with a firm's existing knowledge base. 
Table 1 Descriptive statistics and correlation

\begin{tabular}{|c|c|c|c|c|c|c|c|c|c|c|c|c|c|c|c|c|c|c|c|c|c|}
\hline & Mean & SD & 1 & 2 & 3 & 4 & 5 & 6 & 7 & 8 & 9 & 10 & 11 & 12 & 13 & 14 & 15 & 16 & 17 & 18 & 19 \\
\hline 1. New product & 1.99 & 7.12 & 1.00 & & & & & & & & & & & & & & & & & & \\
\hline 2. Search depth & 0.00 & 0.45 & $0.15^{*}$ & 1.00 & & & & & & & & & & & & & & & & & \\
\hline 3. Knowledge depth & 0.00 & 2.57 & $0.45^{*}$ & $0.49^{*}$ & 1.00 & & & & & & & & & & & & & & & & \\
\hline 4. Knowledge scope & 0.00 & 0.31 & $0.21^{*}$ & $0.33^{*}$ & $0.35^{*}$ & 1.00 & & & & & & & & & & & & & & & \\
\hline 5. Technological opportunities & 0.00 & 11.80 & $0.08^{*}$ & $0.38^{*}$ & $0.43^{*}$ & $0.43^{*}$ & 1.00 & & & & & & & & & & & & & & \\
\hline 6. Year 1990 & 0.07 & 0.26 & 0.01 & $-0.08^{*}$ & -0.05 & -0.05 & -0.06 & 1.00 & & & & & & & & & & & & & \\
\hline 7. Year 1991 & 0.08 & 0.28 & -0.02 & $-0.08^{*}$ & -0.05 & -0.04 & -0.05 & $-0.09^{*}$ & 1.00 & & & & & & & & & & & & \\
\hline 8. Year 1992 & 0.09 & 0.28 & -0.02 & $-0.06^{*}$ & -0.05 & -0.04 & -0.05 & $-0.09^{*}$ & $-0.09^{*}$ & 1.00 & & & & & & & & & & & \\
\hline 9. Year 1993 & 0.09 & 0.29 & 0.00 & -0.06 & -0.03 & -0.02 & -0.04 & $-0.09^{*}$ & $-0.10^{*}$ & $-0.10^{*}$ & 1.00 & & & & & & & & & & \\
\hline 10. Year 1994 & 0.09 & 0.29 & 0.02 & -0.04 & -0.01 & 0.00 & -0.03 & $-0.09^{*}$ & $-0.10^{*}$ & $-0.10^{*}$ & $-0.10^{*}$ & 1.00 & & & & & & & & & \\
\hline 11. Year 1995 & 0.10 & 0.30 & -0.01 & -0.05 & -0.02 & 0.00 & -0.05 & $-0.10^{*}$ & $-0.10^{*}$ & $-0.11^{*}$ & $-0.11^{*}$ & $-0.11^{*}$ & 1.00 & & & & & & & & \\
\hline 12. Year 1996 & 0.11 & 0.31 & 0.00 & 0.00 & 0.01 & -0.02 & -0.02 & $-0.10^{*}$ & $-0.10^{*}$ & $-0.11^{*}$ & $-0.11^{*}$ & $-0.11^{*}$ & $-0.12^{*}$ & 1.00 & & & & & & & \\
\hline 13. Year 1997 & 0.10 & 0.30 & 0.00 & 0.05 & 0.04 & 0.01 & 0.05 & $-0.09^{*}$ & $-0.10^{*}$ & $-0.10^{*}$ & $-0.11^{*}$ & $-0.11^{*}$ & $-0.11^{*}$ & $-0.11^{*}$ & 1.00 & & & & & & \\
\hline 14. Year 1998 & 0.10 & 0.30 & 0.00 & $0.10^{*}$ & 0.04 & 0.04 & $0.09^{*}$ & $-0.09^{*}$ & $-0.10^{*}$ & $-0.10^{*}$ & $-0.10^{*}$ & $-0.10^{*}$ & $-0.11^{*}$ & $-0.11^{*}$ & $-0.11^{*}$ & 1.00 & & & & & \\
\hline 15. Year 1999 & 0.09 & 0.29 & 0.04 & $0.13^{*}$ & $0.06^{*}$ & 0.05 & $0.08^{*}$ & $-0.09^{*}$ & $-0.09^{*}$ & $-0.10^{*}$ & $-0.10^{*}$ & $-0.10^{*}$ & $-0.11^{*}$ & $-0.11^{*}$ & $-0.10^{*}$ & $-0.10^{*}$ & 1.00 & & & & \\
\hline 16. Diversification & 0.17 & 0.38 & 0.04 & $0.15^{*}$ & $0.12^{*}$ & $0.19^{*}$ & $0.14^{*}$ & $-0.07^{*}$ & $-0.09^{*}$ & $-0.10^{*}$ & $-0.10^{*}$ & $-0.10^{*}$ & $-0.11^{*}$ & $-0.11^{*}$ & $-0.12^{*}$ & -0.06 & $0.31^{*}$ & 1.00 & & & \\
\hline 17. Research size & -32.05 & 177.10 & 0.05 & $0.07^{*}$ & $0.10^{*}$ & $0.12^{*}$ & $0.13^{*}$ & $-0.06^{*}$ & 0.02 & -0.01 & 0.01 & 0.02 & 0.05 & 0.01 & 0.01 & -0.04 & 0.01 & 0.01 & 1.00 & & \\
\hline 18. Performance & -0.32 & 0.64 & $0.13^{*}$ & 0.06 & $0.11^{*}$ & $0.23^{*}$ & $0.12^{*}$ & 0.02 & 0.05 & 0.00 & 0.00 & 0.00 & -0.06 & 0.03 & -0.05 & -0.04 & 0.02 & $0.10^{*}$ & -0.02 & 1.00 & \\
\hline 19. Demand growth & 0.63 & 2.84 & -0.01 & 0.03 & $0.07^{*}$ & -0.03 & 0.01 & 0.03 & -0.04 & -0.05 & 0.00 & -0.01 & -0.03 & 0.05 & 0.04 & -0.02 & -0.03 & -0.03 & -0.01 & $-0.07^{*}$ & 1.00 \\
\hline
\end{tabular}


Table 2 Multicollinearity test

\begin{tabular}{lll}
\hline Variable & VIF & $\mathbf{1 / \text { VIF }}$ \\
\hline Year 1997 & 3.31 & 0.30 \\
Year 1996 & 3.28 & 0.31 \\
Year 1993 & 3.10 & 0.32 \\
Year 1998 & 3.09 & 0.32 \\
Year 1992 & 3.05 & 0.33 \\
Year 1994 & 2.99 & 0.33 \\
Year 1995 & 2.99 & 0.33 \\
Year 1991 & 2.69 & 0.37 \\
Year 1990 & 2.50 & 0.40 \\
Diversification & 2.27 & 0.44 \\
Year 1999 & 2.15 & 0.46 \\
Knowledge depth & 1.50 & 0.67 \\
Search depth & 1.47 & 0.68 \\
Knowledge scope & 1.44 & 0.69 \\
Technological opportunities & 1.42 & 0.70 \\
Performance & 1.08 & 0.93 \\
Research size & 1.04 & 0.96 \\
Demand growth & 1.03 & 0.97 \\
Mean VIF & 2.20 & \\
\hline
\end{tabular}

We find a marginal support for the argument that search depth will have a curvilinear relationship with innovative performance. This finding is unexpected as previous studies have shown significant effects for search depth. For example, Katila and Ahuja (2002) apply the same measure in the robotics industry and find that both the firstorder term and the second-order term of search depth are statistically significant. There are two possible explanations. First, an insignificant effect may be due to the low variance in the degree of deep search in our sampled firms. That is, the sampled firms are all public firms, which are large in size and are committed to innovation. So, the degree of search depth is very similar across firms. To examine this possibility, we check the distribution of search depth. Among the 1,157 firm-year observations, 719 cases have the degree of search depth of 0 , accounting for approximately $63 \%$ of the sample. Therefore, the invariance of search depth among sampled firms may help explain its insignificance.

The second explanation of our depth results concerns the role of search depth in the electrical medical device industry. As industry analysts point out, this industry is characterized by many incremental improvements over current devices and equipment. Thus, deep search may help such marginal improvement. However, for the creation of brand new products, or generation of original technology, search depth is not helpful. This argument is consistent with Ahuja and Lampert's (2001) findings that novel and emerging knowledge elements help generate important technological breakthroughs.

Our key findings concern the significant moderating roles of current knowledge base on the relationship between search depth and innovative performance. Of the three interaction models for the generation of new products, we find that two models provide significant supports for our hypotheses. In support of hypothesis 3, a negative coefficient for the 
Table 3 Random effects logistic regression for new products

\begin{tabular}{|c|c|c|c|c|c|c|}
\hline & 1 & 2 & 3 & 4 & 5 & 6 \\
\hline Search depth & & $\begin{array}{l}-0.02 \\
(0.12)\end{array}$ & $0.58^{*}(0.28)$ & $0.70^{*}(0.28)$ & $0.34(0.30)$ & $0.46(0.31)$ \\
\hline $\begin{array}{l}\text { Search depth } \\
\text { squared }\end{array}$ & & & $\begin{array}{l}-0.25 \wedge \\
(0.14)\end{array}$ & $\begin{array}{l}-0.23 \wedge \\
(0.13)\end{array}$ & $\begin{array}{l}-0.27 \wedge \\
(0.14)\end{array}$ & $\begin{array}{l}-0.25 \wedge \\
(0.14)\end{array}$ \\
\hline $\begin{array}{l}\text { Search depth } \times \\
\text { knowledge depth }\end{array}$ & & & & $-0.08 *(0.04)$ & & \\
\hline $\begin{array}{l}\text { Search depth } \times \\
\text { knowledge scope }\end{array}$ & & & & & $1.08^{* *}(0.37)$ & \\
\hline $\begin{array}{l}\text { Search depth } \times \\
\text { technological } \\
\text { opportunities }\end{array}$ & & & & & & $0.01(0.01)$ \\
\hline $\begin{array}{l}\text { Knowledge } \\
\text { depth }\end{array}$ & $0.06^{* *}(0.02)$ & $0.06^{* *}(0.02)$ & $0.07^{* *}(0.02)$ & $0.10^{* * *}(0.03)$ & $0.07^{* * *}(0.02)$ & $0.07^{* *}(0.02)$ \\
\hline $\begin{array}{l}\text { Knowledge } \\
\text { scope }\end{array}$ & $0.41 \wedge(0.22)$ & $0.40 \wedge(0.22)$ & $0.44 \wedge(0.23)$ & $0.39 \wedge(0.23)$ & $0.41 \wedge(0.23)$ & $0.44 \wedge(0.23)$ \\
\hline $\begin{array}{l}\text { Technological } \\
\text { opportunities }\end{array}$ & $0.00(0.01)$ & $0.00(0.01)$ & $0.00(0.01)$ & $0.00(0.01)$ & $0.00(0.01)$ & $0.00(0.01)$ \\
\hline Year 1990 & $0.34(0.28)$ & $0.34(0.28)$ & $0.37(0.28)$ & $0.30(0.28)$ & $0.40(0.28)$ & $0.36(0.28)$ \\
\hline Year 1991 & $0.01(0.29)$ & $0.01(0.29)$ & $0.03(0.29)$ & $-0.03(0.29)$ & $0.05(0.29)$ & $0.02(0.29)$ \\
\hline Year 1992 & $0.07(0.28)$ & $0.07(0.28)$ & $0.09(0.28)$ & $0.02(0.28)$ & $0.11(0.28)$ & $0.08(0.28)$ \\
\hline Year 1993 & $0.17(0.28)$ & $0.17(0.28)$ & $0.21(0.28)$ & $0.15(0.28)$ & $0.22(0.28)$ & $0.20(0.28)$ \\
\hline Year 1994 & $0.35(0.26)$ & $0.35(0.26)$ & $0.39(0.26)$ & $0.34(0.26)$ & $0.41(0.26)$ & $0.38(0.26)$ \\
\hline Year 1995 & $0.14(0.27)$ & $0.13(0.27)$ & $0.16(0.27)$ & $0.11(0.27)$ & $0.20(0.27)$ & $0.15(0.27)$ \\
\hline Year 1996 & $0.36(0.26)$ & $0.37(0.26)$ & $0.37(0.25)$ & $0.34(0.25)$ & $0.39(0.25)$ & $0.37(0.25)$ \\
\hline Year 1997 & $0.27(0.26)$ & $0.26(0.26)$ & $0.28(0.26)$ & $0.23(0.26)$ & $0.26(0.26)$ & $0.27(0.26)$ \\
\hline Year 1998 & $0.17(0.26)$ & $0.16(0.26)$ & $0.19(0.26)$ & $0.14(0.26)$ & $0.19(0.26)$ & $0.18(0.25)$ \\
\hline Year 1999 & $\begin{array}{l}0.34 \wedge \\
(0.19)\end{array}$ & $\begin{array}{l}0.34 \wedge \\
(0.19)\end{array}$ & $0.38^{*}(0.19)$ & $0.37 \wedge(0.19)$ & $0.39 *(0.19)$ & $0.37 \wedge(0.19)$ \\
\hline Diversification & $0.18(0.19)$ & $0.20(0.19)$ & $0.22(0.19)$ & $0.18(0.19)$ & $0.20(0.19)$ & $0.20(0.19)$ \\
\hline Research size & $0.00^{*}(0.00)$ & $0.00^{*}(0.00)$ & $0.00^{*}(0.00)$ & $0.00 *(0.00)$ & $0.00 *(0.00)$ & $0.00^{*}(0.00)$ \\
\hline Performance & $0.35^{*}(0.14)$ & $0.35^{*}(0.14)$ & $0.34^{*}(0.14)$ & $0.36^{*}(0.15)$ & $0.31^{*}(0.14)$ & $0.34^{*}(0.14)$ \\
\hline $\begin{array}{l}\text { Demand } \\
\text { growth }\end{array}$ & $0.02(0.01)$ & $0.02(0.01)$ & $0.02(0.01)$ & $0.02(0.01)$ & $0.02(0.01)$ & $0.02(0.01)$ \\
\hline Constant & $0.34(0.27)$ & $0.33(0.27)$ & $0.03(0.30)$ & $0.09(0.30)$ & $0.02(0.30)$ & $0.04(0.30)$ \\
\hline Log likelihood & $-1,395.6$ & $-1,395.1$ & $-1,391.9$ & $-1,389.5$ & $-1,387.3$ & $-1,391.5$ \\
\hline Wald chi-square $(d f)$ & $43.6(17)$ & $45.4(18)$ & $52.7(19)$ & $56.5(20)$ & $66.4(20)$ & $53.7(20)$ \\
\hline
\end{tabular}

Standard errors are shown in parentheses. There are 955 firm-year observations and 141 sampled firms for analysis. $\wedge p<$ $0.10,{ }^{*} p<0.05,{ }^{* *} p<0.01,{ }^{* * *} p<0.001$.

interaction between knowledge depth and search depth indicates that knowledge depth plays a negative moderating role on the linkage between search depth and new product introduction, consistent with prior research claiming a diminishing return to technology. As Fleming (2001: 120) points out, '... the benefits of familiarity do not last forever. This results from the technological and social-psychological exhaustion of potential refinements, given a particular combination'. So, if a firm has already accumulated deep knowledge in a technological domain, further exploitation of current knowledge may constrain its innovative competence, due to both technological and social-psychological exhaustion. This finding also provides some empirical evidence of 'competency traps' (Levinthal and March 1993). Firms 
tend to conduct local search around their expertise. While this tendency avoids uncertainty, it also may hurt innovation and adaptation.

On the other hand, if a firm's knowledge base covers a wide variety of technological domains, deep search may be beneficial. This is indicated by the significantly positive coefficient of the interaction between knowledge scope and search depth. This supports hypothesis 4 and suggests that knowledge scope plays a positive moderating effect on the relationship between search depth and innovation.

Overall, we find general support for the argument that the effects of search behaviors on innovative performance are moderated by the characteristics of a firm's existing knowledge base. Over-exploitation will negatively affect innovative performance (at least when the number of new products is used as the performance measure). When a firm engages in technological search, it must consider the depth, scope, and opportunities associated with its current knowledge base.

Thus, our study contributes to the existing literature by applying the knowledgebased view to investigate how exploitation and knowledge stock interact with each other and influence the innovative outcome. In particular, we extend the current literature by identifying three dimensions of the characteristics of a firm's knowledge stock and investigating their moderating effects on exploitation.

This study has several limitations. First, it focuses on the innovative performance of US public firms and thus may not generalize to smaller or private firms. We also limit our attention to a single industry, which may also limit the potential for generalizing our results. Future work can include other high-tech industries and assure a better distribution of firms by size and governance arrangements. This study also proxies a firm's knowledge base by patents, which is a legal form that protects a firm's intellectual properties. However, not all firms protect their technological assets with patents. Some may prefer to keep their know-how as trade secrets. New knowledge on other industries may not be as conducive to patent protection as medical devices. Future work might consider the distribution of different types of intellectual properties in a firm's knowledge base. Finally, we have not examined the quality of innovation. As Nelson and Winter (1982) and March (1991) suggest, local search and distant search may result in different types of innovation. Different types of searches may impact future technologies in different ways (Rosenkopf and Nerkar 2001). More research on the effects of technological search on innovation quality is needed.

Competing interests

The authors declare that they have no competing interests.

Authors' contributions

J Wu and Y Wang proposed the original idea and drafted the manuscript, and S Li conducted the data collection and statistical analyses. All authors read and approved the final manuscript.

Authors' information

J Wu (PhD, Purdue University) is a professor of strategic management at the University of International Business and Economics. His research mainly focuses on social networks, technological innovation, and internationalization of Chinese firms. His work has appeared in the Asia Pacific Journal of Management, Journal of Business Research, and Organization Science.

\section{Acknowledgements}

This research is supported by the Social Science Foundation of the Ministry of Education of China (10YJC630278) and the National Social Science Foundation of China (11\&ZD004 and 12\&ZD205). 


\section{References}

Ahuja G (2000) Collaboration networks, structural holes, and innovation: a longitudinal study. Adm Sci Q 45:425-455

Ahuja G (2003) When atlas shrugged: preemption, complexity, and division of labor in a theory of appropriability. Working paper. University of Michigan, Ann Arbor

Ahuja G, Katila R (2001) Technological acquisitions and the innovation performance of acquiring firms: a longitudinal study. Strategic Manage J 22:197-220

Ahuja G, Lampert CM (2001) Entrepreneurship in the large corporation: a longitudinal study of how established firms create breakthrough inventions. Strategic Manage I 22:521-543

Argote I (1999) Organizational learning: creating, retaining, and transferring knowledge. Kluwer, Boston

Bierly P, Chakrabarti A (1996) Generic knowledge strategies in the U.S. pharmaceutical industries. Strategic Manage J 17:123-135

Christensen C (2000) The innovator's dilemma. Harper Business, New York

Cohen WM, Levinthal DA (1990) Absorptive capacity: a new perspective on learning and innovation. Admin Sci Quart 35:128-152

Cronbach L (1987) Statistical tests for moderator variables: flaws in analyses recently proposed. Psychol Bull 102:414-417

Cyert RM, March JG (1963) A behavioral theory of the firm. Englewood Cliffs, Prentice Hall

Fleming L (2001) Recombinant uncertainty in technological search. Manag Sci 47:117-132

Fung MK (2002) Technological opportunity and economies of scale in research productivity: a study on three global industries. Rev Ind Organ 21:419-436

Fung MK (2004) Technological opportunities and productivity of R\&D activities. J Prod Anal 21:167-181

Hall BH, Jaffe AB, Tratjenberg M (2001) The NBER patent citation data file: Lessons, insights, and methodological tools. NBER working paper 8498

Hausman J, Hall BH, Griliches Z (1984) Econometric models for count data with an application to the patents-R\&D relationship. Econometrica 52:909-938

Henderson RM (1995) Of life cycles real and imaginary: the unexpectedly long old age of optical lithography. Res Policy 24:631-643

Henderson RM, Cockburn I (1996) Scale, scope, and spillovers: the determinants of research productivity in drug discovery. RAND J Econ 27:32-59

Hill CWL, Hitt MA, Hoskisson RE (1988) Declining U.S. competitiveness: innovation, the M-form structure, and the capital markets. Acad Manage Exec 2:51-60

Katila RA, Ahuja G (2002) Something old, something new: a longitudinal study of search behavior and new product introduction. Acad Manage J 45:1183-1194

Kim DJ, Kogut B (1996) Technological platforms and diversification. Organ Sci 7:283-301

Klevorick AK, Levin RC, Nelson RR, Winter SG (1995) On the sources and significance of interindustry differences in technological opportunities. Research Policy 24:185-205

Lanjouw JO, Schankerman M (1999) The quality of ideas: Measuring innovation with multiple indicators. NBER working paper 7345

Leonard-Barton D (1992) Core capabilities and core rigidities: a paradox in managing new product development. Strategic Manage J 13(special issue):111-125

Lerner J (1994) The important of patent scope: an empirical analysis. RAND J Econ 25:319-333

Levinthal DA, March JG (1993) The myopia of learning. Strategic Manage J 14(special issue):95-112

Madansky A (1988) Prescriptions for working statisticians. Springer, New York

Maddala GS (1987) Limited dependent variable models using panel data. J Hum Resour 22:305-338

March JG (1991) Exploration and exploitation in organizational learning. Organ Sci 2(special issue):71-87

McEvily SK, Yao B (2004) Getting the right mix: the roles of absorptive capacity and network connections in technology innovation. Working paper. University of Pittsburgh, Pittsburgh

McGrath RG, Nerkar A (2004) Real options reasoning and a new look at the R\&D investment strategies of pharmaceutical firms. Strategic Manage I 25:1-21

Nelson RR, Winter SG (1982) An evolutionary theory of economic change. Belknap, Cambridge

Palepu K (1985) Diversification strategy, profit performance and the entropy measure. Strategic Manage J 6:239-255

Penrose ET (1959) The theory of the growth of the firm. Blackwell, Oxford

Pisano G (1996) Learning-before-doing in the development of new process technology. Res Policy 25:1097-1119

Rosenkopf L, Nerkar A (2001) Beyond local search: boundary-spanning, exploration, and impact in the optical disk industry. Strategic Manage J 22:287-306

Sahal D (1985) Technological guideposts and innovation avenues. Research Policy 14:61-82

Steensma K, Corley K (2000) On the performance of technology-sourcing partnerships: the interaction between partner interdependence and technology attributes. Acad Manage J 43:1045-1067

Stuart TE, Podolny JM (1996) Local search and the evolution of technological capabilities. Strategic Manage J 17(special issue):21-38

Williamson OE (1975) Markets and hierarchy: analysis and antitrust applications. McMillan, New York

Wu J, Shanley M (2009) Knowledge stock, exploration, and innovation: research on the United States electromedical industry. J Bus Res 62:474-483

Yayavaram S (2003) Structure of a firm's knowledge base and the effectiveness of technological search. Unpublished Doctoral Dissertation. University of Texas, Austin

doi:10.1186/s40527-014-0002-8

Cite this article as: Wu et al: Search depth, knowledge characteristics, and innovation performance. Journal of Chinese Management 2014 1:2. 